\title{
Dampak Masuknya Imigran Timur Tengah terhadap Keamanan Manusia Domestik dan Respon Kebijakan Amerika Serikat Era Donald Trump
}

\author{
Lucitania Rizky \\ Universitas Teknologi Yogyakarta \\ Email: lucitania.rizky@staff.uty.ac.id
}

\author{
Heru Siswoyo Kurniawan Bin Supriyadi \\ Universitas Teknologi Yogyakarta \\ Email: herucitizen97@gmail.com
}

\begin{abstract}
Abstrak
Keresahan AS terhadap datangnya imigran Timur Tengah menjadi salah satu fokus utama kebijakan luar negeri pada era pemerintahan Trump. Dengan menggunakan alat analisis konsep keamanan manusia dan kebijakan luar negeri, studi ini bertujuan menjelaskan kebijakan luar negeri AS di era Trump sebagai respon terhadap masuknya gelombang imigran Timur Tengah yang mengancam sektor keamanan personal domestik AS. Kebijakan yang dikeluarkan dari pemerintahan Trump, tidak terlepas dari pandangan Islamophobia yang dimiliki Trump, sehingga menghasilkan produk kebijakan luar negeri terhadap imigran Timur Tengah yang bersifat kontradiktif dengan era pemerintah sebelumnya. Studi ini menggunakan metode penelitian analisis kualitatif-deskriptif, dengan teknik pengumpulan data sekunder. Dalam studi ini ditemukan beberapa strategi kebijakan luar negeri Trump sebagai agenda meningkatkan dan mempertahankan keamanan manusia domestik AS yakni Border Security and Interior Enforcement dan perintah eksektutif "Protecting the Nation from Terrorist Attacks by Foreign National" melalui travel ban.
\end{abstract}

Kata Kunci: Imigran timur tengah, era Trump, kebijakan luar Negeri Amerika Serikat, kemanan manusia.

\begin{abstract}
The U.S anxiety about Middle Eastern immigrants became one of the main concerns of foreign policy in the Trump era. By using human security and foreign policy concepts as the analysis tools, this study aims at describing US foreign policy in Trump's era as the response to the influx of Middle Eastern immigrants waves that threaten U.S domestic personal security. The policy issued by Trump's era was inspirable from the Islamophobia perspective that resulted in contradictive foreign policy with previous government's era. This study adopts a descriptive-qualitative approach with secondary data collection techniques. This study found some strategies foreign policy from Trump's era as agendas to improve and maintain U.S domestic security. Those are Border Security and Interior Enforcement and executive order "Protecting the Nation from Terrorist Attacks by Foreign National" through travel ban.
\end{abstract}

Keywords: Middle eastern immigrant, Trumps's era, the US foreign policy, human security.

DOI: $10.36341 / j d p . v 4 i 2.1944$

\section{PENDAHULUAN}

Isu imigran menjadi sebuah isu yang cukup sensitif di negara-negara barat. Imigran sering dianggap sebagai tantangan tersendiri bagi konstelasi politik dalam negeri suatu negara sehingga hal ini banyak memicu perdebatan baik di kalangan praktisi maupun akademisi. Badan Migrasi Persatuan Bangsa-Bangsa (PBB), International Organization for Migration (IOM) menetapkan bahwa seorang imigran merupakan 
orang yang bergerak atau telah melintasi perbatasan internasional atau dalam suatu negara yang diperkirakan jauh dari tempat asalnya, terlepas dari (1) status hukum orang tersebut, (2) termasuk dalam gerakan sukarela atau tidak sukarela, (3) apa penyebab gerakan itu, atau (4) lamanya jangka waktu seseorang untuk tinggal dalam suatu negara tersebut (International Organization for Migration 2013).

Praktik migrasi sangat erat hubungannya dengan isu pembangunan internasional. Banyaknya interaksi aktor-aktor hubungan internasional dan berkembangnya teknologi perpindahan penduduk semakin mempermudah praktik migrasi dari suatu negara ke negara lainnya baik secara legal maupun ilegal. Secara teoritis, migrasi antar negara atau migrasi internasional merupakan sebuah fenomena global yang berkembang dan merupakan sebab dan akibat dari proses pembangunan yang lebih luas secara global. Migrasi dapat menjadi kekuatan positif untuk pembangunan ketika didukung oleh serangkaian kebijakan yang tepat. Pada umumnya, munculnya migrasi internasional disebabkan oleh keinginan imigran untuk memiliki rasa aman dan hidup yang lebih sejahtera ketika negara asal sedang mengalami konflik atau perang. Hal ini juga berdampak pada kompleksitas masalah pemerintah negara penerima dan juga bagi dunia dalam menangani isu imigran. Di sisi lain, data mengenai imigran juga mengalami tren kenaikan dari tahun ke tahun. (Lihat Grafik 1.)

Salah satu negara yang memiliki hubungan erat dengan praktik migrasi adalah Amerika Serikat (AS). AS merupakan negara penerima imigran terbesar di dunia baik untuk mencari suaka maupun keamanan. Ekspektasi untuk hidup di negeri Paman Sam tersebut mengakibatkan banyak orang ingin meninggalkan tanah kelahiran mereka demi mendapatkan kehidupan yang lebih layak terutama bagi warga negara asing Timur Tengah yang mengalami krisis ekonomi maupun peperangan. Alasan imigran Timur Tengah memilih AS sebagai tempat pengungsi daripada Eropa adalah bahwa negara AS sendiri merupakan "bangsa imigran". Julukan tersebut mewakili banyaknya imigran asing yang tidak hanya dari berasal dari Timur Tengah tetapi dari berbagai penjuru dunia. Hal ini juga diperkuat oleh sejarah bahwa penduduk asli AS adalah orang Indian dan mayoritas bukan berasal dari orang kulit putih yang berarti bahwa penduduk AS saat ini merupakan imigran. Ini diawali oleh orang kulit putih (Eropa) yang masuk ke AS untuk menetap dikarenakan melihat bahwa wilayah yang dikenal sebagai AS tersebut memiliki prospek ekonomi yang besar kedepannya (Weisberger 1994). Selain itu, negara AS sendiri memiliki prinsip yaitu American Values yang sangat menjunjung tinggi nilai moral dan bersifat terbuka kepada siapapun. 
Grafik 1. Imigran di Amerika Serikat, 1820 - 2010

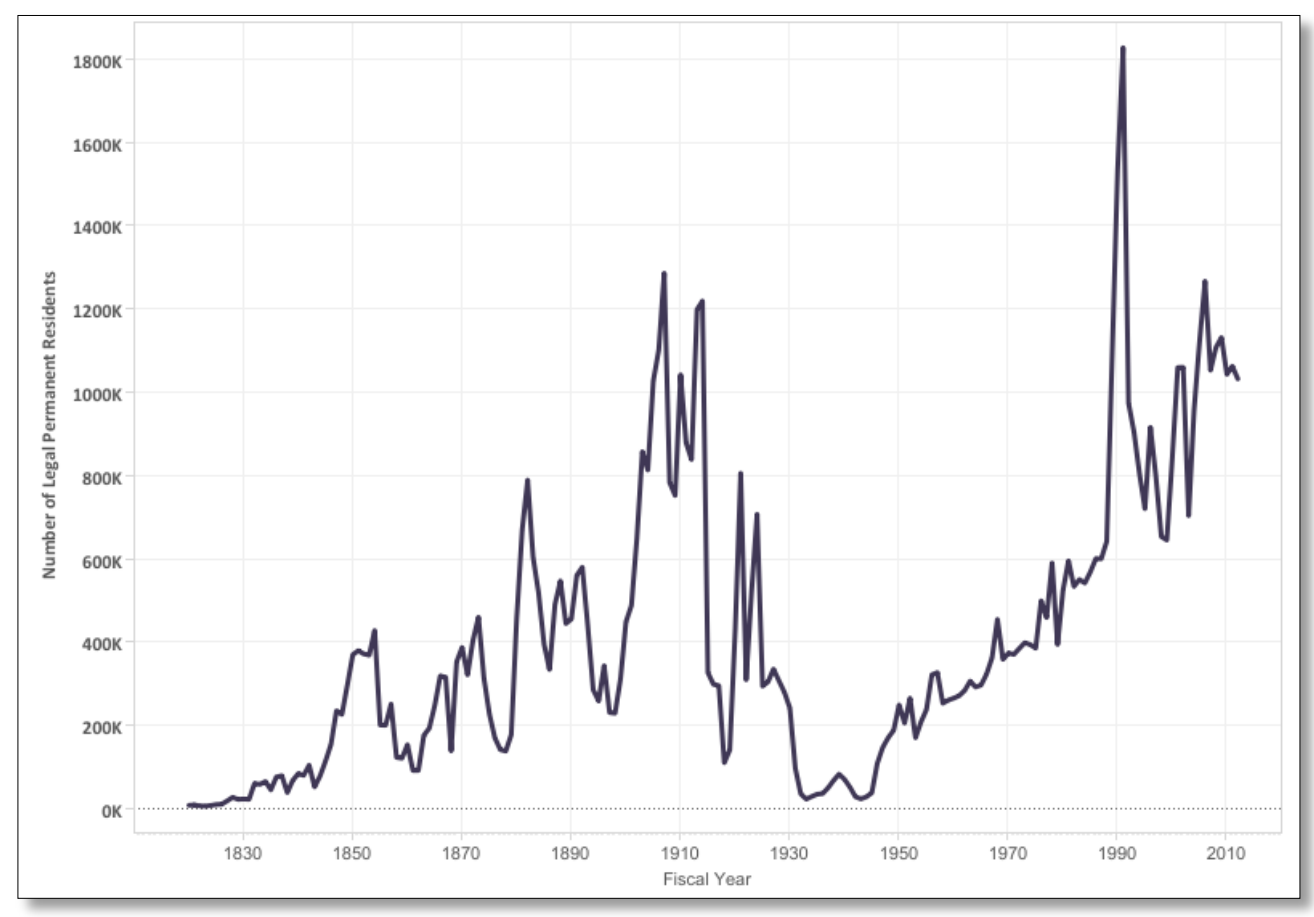

Sumber : Migration Policy Institute tabulations of U.S. Department of Homeland Security, Office of Immigration Statistics, Yearbook of Immigration Statistics (various years). Dapat diakses pada: www.dhs.gov/files/statistics/publications/yearbook.shtm

Secara umum terdapat dua faktor utama yang mendasari imigran Timur Tengah untuk masuk ke AS yaitu faktor ekonomi dan faktor keamanan dan kebebasan. Faktor ekonomi merupakan salah satu hal yang terpenting agar mereka bisa bertahan hidup dengan lebih layak dibandingkan di negara mereka sendiri terlebih lagi negara bagian Timur Tengah yang memiliki banyak konflik. Kehidupan yang lebih mapan membuat para imigran tersebut menjadi rela untuk migrasi dan tinggal di AS (Saba 2015). Ini ditunjang dengan fakta bahwa secara ekonomi, AS merupakan negara dengan perekonomian yang maju dan AS juga masuk dalam keanggotaan United Nations High Commissioner for Refugees (UNHCR) sehingga AS diharapkan mampu menerima imigran yang negaranya sedang mengalami konflik. Yang kedua terkait dengan keamanan dan kebebasan. Ini dikarenakan faktor negara asal mereka sudah tidak lagi aman dan banyak konflik yang terjadi. Oleh sebab itu, para imigran mencari keamanan yang lebih layak untuk menghindari kemiskinan dan tidak lagi menginginkan mati secara sia-sia apalagi AS juga dapat memberikan beberapa fasilitas seperti prosedur birokrasi yang tertib, layanan publik yang serba online dan penyediaan rumah bagi yang tidak mampu.

Singkatnya, banyaknya imigran Timur Tengah datang ke AS dengan membawa harapan yang besar agar mereka bisa bertahan hidup, mencari kehidupan dan perekonomian yang lebih mapan, memiliki kebebasan dalam berpolitik, beragama dan berbagai harapan lainnya. Tidak sedikit dari mereka yang berhasil mendapatkan apa yang diharapkannya ketika menjadi imigran, itulah yang dikenal dengan istilah American Dream (Syekhnurjati 2018). 
Tabel 1. Negara Timur Tengah dan Afrika Utara (MENA) Penyumbang Imigran

\begin{tabular}{|c|r|r|}
\hline Country and Region & Number of Immigrants & Percent (\%) \\
\hline MENA Total & $1,167,000$ & 100.0 \\
\hline Middle East & 810,000 & 69.4 \\
\hline Iraq & 222,000 & 19.0 \\
\hline Lebanon & 129,000 & 11.0 \\
\hline Saudi Arabia & 100,000 & 8.6 \\
\hline Syria & 97,000 & 8.3 \\
\hline Other Western Asia & 83,000 & 7.1 \\
\hline Jordan & 82,000 & 7.0 \\
\hline Yemen & 62,000 & 5.3 \\
\hline Kuwait & 37,000 & 3.1 \\
\hline North Africa & 358,000 & 30.6 \\
\hline Egypt & 182,000 & 15.6 \\
\hline Morocco & 80,000 & 6.9 \\
\hline Other Northern Africa & 56,000 & 4.8 \\
\hline Sudan & 39,000 & 3.4 \\
\hline
\end{tabular}

Sumber : MPI tabulation of data from the U.S. census Bureau 2016 ACS. Dapat diakses pada https://www.migrationpolicy.org/

Masuknya imigran dari Timur Tengah menunjukkan bahwa setidaknya AS konsisten terhadap prinsip American Values dan mengimplementasikan perjanjian internasional yang telah diratifikasi sebelumnya seperti Konvensi 1951 dan Protokol 1967 mengenai pengungsi. Namun di sisi lain, banyaknya imigran dapat mengakibatkan masalah-masalah domestik AS. Penulis melihat bahwa masuknya imigran Timur Tengah berdampak pada human security atau keamanan manusia masyarakat domestik AS. Dalam tulisan ini, penulis akan memaparkan dampak masuknya imigran Timur Tengah terhadap keamanan manusia AS khususnya keamanan personal. Penulis juga akan menjelaskan respon dari pemerintahan AS di bawah Donald Trump terhadap masuknya para imigran tersebut.

\section{Konsep Keamanan Manusia}

Konsep keamanan manusia memiliki makna yang sangat luas sehingga pemahaman tentang konsep keamanan dalam sudut pandang pemikiran tradisional tidak lagi digunakan untuk melihat hubungan internasional di era kontemporer sekarang ini. Jika kaum tradisionalis mengidentifikasi keamanan sebagai hal-hal yang berhubungan dengan militerisme, maka pemaknaan secara kontemporernya tentu saja berbeda. Keamanan manusia itu sendiri secara luas mencakup isu-isu non militer (Ikbar 2014). Terdapat tujuh jenis keamanan dalam keamanan manusia seperti keamanan politik, ekonomi, individu, lingkungan, kesehatan, pangan dan komunitas. Adapun dalam buku yang menjelaskan secara ringkas United Nation Development Programme (UNDP) mendefinisikan keamanan manusia sebagai:

"First, safety from such chronic threats such as hunger, disease, and repression. And second, it means protection from sudden and hurtful disruptions in the patterns of daily life whether in homes, in jobs or in communities. Such threats can exist at all levels of national income and development." (UNDP 2010) 


\section{Tabel 2. Keamanan Manusia Versi PBB}

\begin{tabular}{|c|c|c|}
\hline Type of Security & Definition & Threats \\
\hline Economic Security & An assured basic income & $\begin{array}{l}\text { Poverty, unemployment, } \\
\text { indebtedness, lack of income }\end{array}$ \\
\hline Food Security & $\begin{array}{l}\text { Physical and economic access } \\
\text { to basic food }\end{array}$ & $\begin{array}{l}\text { Hungers, Famines, and the lack } \\
\text { of physical and economic } \\
\text { access to basic food }\end{array}$ \\
\hline Health Security & $\begin{array}{l}\text { Protection from diseases and } \\
\text { unhealthy lifestyles }\end{array}$ & $\begin{array}{l}\text { Inadequate healthcare, new and } \\
\text { recurrent diseases including } \\
\text { epidemics, and pandemics, poor } \\
\text { nutrition, and unsafe lifestyles }\end{array}$ \\
\hline Environmental Security & Healthy physical environment & $\begin{array}{l}\text { Environmental degradations, } \\
\text { natural disasters, pollutions, and } \\
\text { resource depletions }\end{array}$ \\
\hline Personal Security & Security from physical violence & $\begin{array}{l}\text { From the state (torture), other } \\
\text { states (wars), group of people } \\
\text { (ethnic tension), individuals or } \\
\text { gangs (crime), industrial, } \\
\text { workplace, or traffic accidents }\end{array}$ \\
\hline Community Security & Safe membership in the groups & $\begin{array}{l}\text { From the group (oppressive } \\
\text { practices), between groups } \\
\text { (ethnic violence), from dominant } \\
\text { groups (e.g indigenous people } \\
\text { vulnerability) }\end{array}$ \\
\hline Political Security & $\begin{array}{l}\text { Living in society that honors } \\
\text { basic human rights }\end{array}$ & $\begin{array}{l}\text { Political or state repression, } \\
\text { including torture, } \\
\text { disappearance, human rights } \\
\text { violations, detentions and } \\
\text { imprisonments }\end{array}$ \\
\hline
\end{tabular}

Sumber: UNDP

Dari tujuh tipe keamanan manusia, peneliti menggunakan satu tipe keamanan manusia yakni keamanan personal. Keamanan individu/personal berkaitan dengan upaya pencegahan, penundaan, dan pengurangan terhadap ancaman kejahatan secara konstruktif. Ini berhubungan dengan pembelaan diri dari adanya kekerasan fisik dan privasi yang tidak boleh dilanggar oleh orang lain. Fen Osler Hampson menunjukkan tiga kemungkinan penjelasan mengenai keamanan individu. Yang pertama mendefinisikan keamanan individu berdasarkan hukum alam dan aturan hukum. Masalah kedua menyangkut pemikiran dan tindakan kemanusiaan yang bertujuan untuk memperkuat hukum internasional tentang genosida dan kejahatan perang, menghapus senjata yang sangat berbahaya bagi warga sipil, dan intervensi kemanusiaan. Yang ketiga terkait dengan gagasan keadilan sosial. Ketiga penjelasan ini terutama berfokus pada isu-isu yang berkaitan dengan pengembangan dan perlindungan hak asasi manusia yang sejalan dengan kebebasan dari keinginan, dan intervensi kemanusiaan yang bertujuan untuk melindungi kehidupan dan hak individu serta cenderung menghindari rasa takut (Hampson 2013).

\section{Konsep Kebijakan Luar Negeri}

K. J. Holsti menyatakan bahwa politik luar negeri adalah strategi atau rencana bagi pengambil keputusan suatu negara untuk berinteraksi dengan negara lain atau elit politik internasional lainnya dan mengambil tindakan untuk mengontrol dan mencapai tujuan nasional, kemudian menerjemahkannya ke dalam istilah terkait demi kepentingan nasionalnya (Holsti 1968). Kebijakan luar negeri adalah studi yang kompleks karena melibatkan tidak hanya faktor eksternal suatu negara, tetapi juga faktor internal suatu negara (Rosenau dkk 1976).

Dalam kajian sistem politik luar negeri, rangsangan dari lingkungan internal dan eksternal untuk mempengaruhi kebijakan luar negeri pengambil keputusan 
berubah menjadi sebuah output. Ini berarti bahwa kebijakan luar negeri merupakan sebuah respon terhadap peristiwa yang terjadi baik di lingkungan domestik maupun lingkungan eksternal dalam kaitannya dengan aktor-aktor luar negeri. Proses transisi yang terjadi dalam perumusan politik luar negeri suatu negara ini mengacu pada makna dari apa yang terjadi di lingkungan pertimbangan internal dan eksternal juga harus diberikan untuk tujuan yang ingin dicapai fasilitas dan kemampuan yang dimilikinya (Rosenau 1980).

Rosenau juga berpendapat bahwa definisi kebijakan luar negeri adalah adopsi keseluruhan sikap dan aktivitas untuk diatasi dan bermanfaat bagi lingkungan eksternal. Menurutnya, kebijakan luar negeri bertujuan untuk menjaga dan menopang kelangsungan hidup suatu negara. Selain itu, menurut Rosenau, jika kita mempelajari kebijakan luar negeri suatu negara, kita akan terjerumus ke dalam fenomena yang luas dan kompleks, antara lain kehidupan internal dan kebutuhan eksternal, termasuk kehidupan internal dan eksternal seperti keinginan, atribut bangsa, budaya, konflik, kapabilitas, kelembagaan, dan kegiatan rutin yang bertujuan mewujudkan dan memelihara karakteristik sosial, hukum, dan geografis suatu negara sebagai negara-bangsa.

\section{METODE PENELITIAN}

Penelitian ini secara utuh menggunakan metode penelitian kualitatif deskriptif yang berperan penting dalam menentukan hasil akhir dari penelitian ini. Analisis kualitatif yang digunakan untuk menelaah teori maupun konsep dan kualitatif deskriptif yang digunakan untuk memaparkan kebijakan luar negeri AS terhadap isu imigran Timur Tengah dalam konteks keamanan manusia. Penulis menggunakan rentang waktu dari 2016 hingga 2019. Ini dikarenakan faktor dari masa jabatan Donald Trump sebagai presiden dan apa saja kebijakan luar negeri AS di bawah kepemimpinannya mengingat banyaknya isu pelarangan imigran muslim yang masuk ke AS. Meskipun demikian, penulis juga menggunakan datadata sebelum tahun 2016 khususnya terkait sejarah masuknya imigran dan dampaknya bagi keamanan personal AS. Teknik pengumpulan data dilakukan dengan menggunakan sumber data sekunder. Ketika data telah terkumpul, penulis akan melakukan proses pengolahan data dari wujud tabel, grafik, dan angka ke dalam bentuk tulisan baru, dengan memberikan analisa yang lebih mendalam. Metode ini bertujuan untuk menjelaskan pada teori atau konsep yang digunakan, untuk itu setiap analisa yang dituliskan penulis akan dibagi ke dalam sub-bab pembahasan.

\section{PEMBAHASAN}

\section{Kilas Balik Imigran Timur Tengah Masuk ke AS}

Pertumbuhan jumlah imigran yang datang ke AS terus mengalami perkembangan. Hal tersebut mengingat bahwa AS merupakan negara adidaya atau negara maju yang mumpuni secara ekonomi. Pertumbuhan ekonomi yang sangat baik juga membuat AS mampu terlibat dan menjadi salah satu negara "super power" di kancah peperangan besar di dunia khususnya Perang Dunia I dan Perang Dunia II. Keterlibatan AS dengan negara-negara besar lainnya seperti Uni Soviet, Jerman, Jepang, Inggris dan lain sebagainya membuat negara ini terus terlibat dalam perang-perang besar lainnya seperti Perang Korea dan Vietnam. 
Pada akhir tahun 1900-an, praktik imigrasi dari Afrika Utara dan Timur Tengah dimulai, atau banyak orang menyebutnya dengan Middle East and North Africa (MENA). Grafik imigran Timur Tengah turut kian meningkat setiap tahunnya. Ini dikarenakan adanya beberapa faktor seperti gejolak politik di Yaman dan Suriah dan peluang ekonomi turut menarik minat bagi imigran Timur Tengah untuk mengungsi dan mencari kehidupan yang lebih mapan dan sejahtera.

\section{Grafik 1. Populasi Imigran MENA (Middle East and Nort Africa) di Amerika, 1980 hingga 2016}

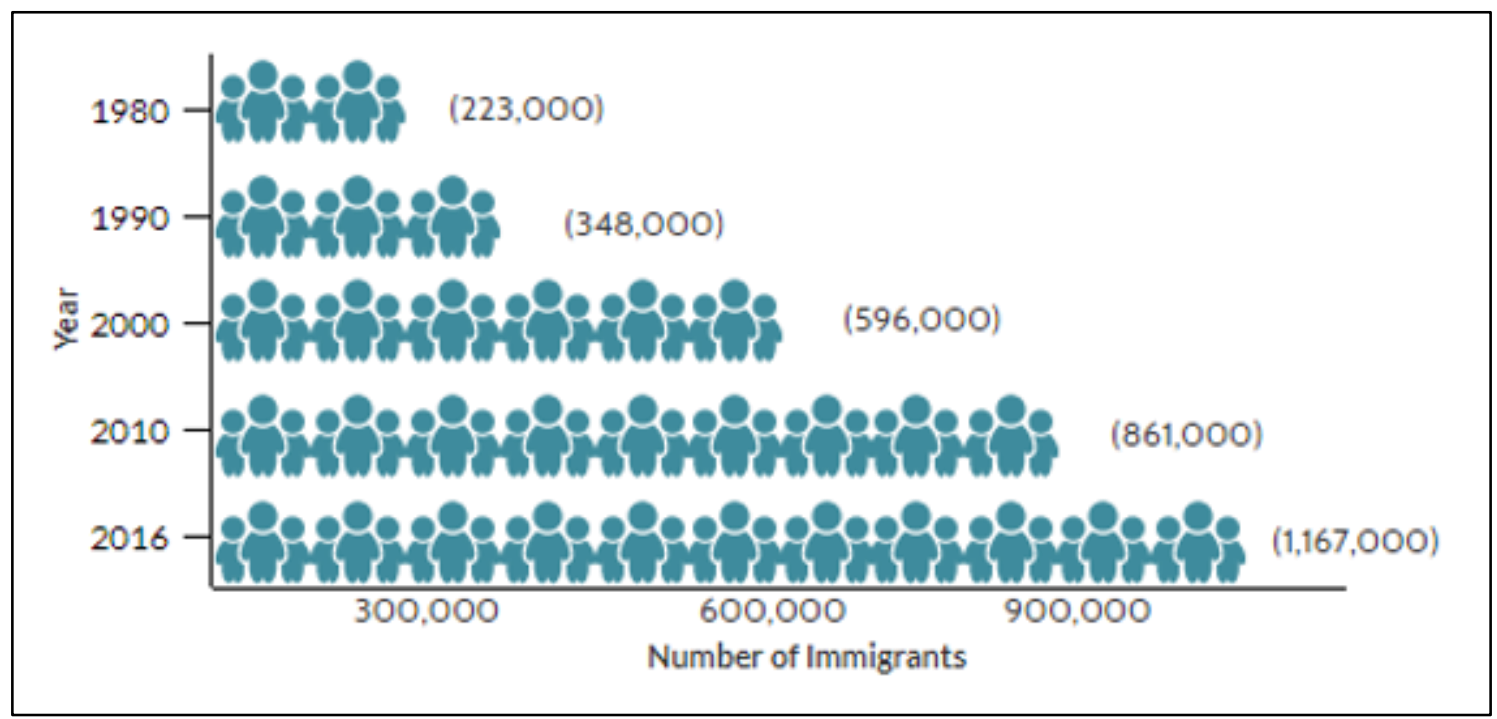

Sumber: Data dari US Census Bureau 2010 dan 2016 American Community Surveys (ACS), Campbell J. Gibson, dan Kay Jung, "Historical Census Statistic on the Foreign-born Population of the United States: 1850-2000" (working Paper No. 81, US Census Bureau, Washingto, DC, february 2006). Dapat diakses pada https://www.migrationpolicy.org/

Migrasi kawasan MENA memiliki tiga fase dengan dimulainya pada abad ke18 (Cumoletti dan Batalova, 2018). Banyaknya imigran MENA yang menetap di AS terdiri dari masyarakat Kristen Arab yang terletak di provinsi Ottoman, Suriah. Provinsi Ottoman itu sendiri merupakan golongan dari orang Lebanon modern, Israel, dan Suriah. Salah satu faktornya adalah dengan melarikan diri dari konflik perang dan buruknya sistem perekonomian yang terjadi di wilayah MENA. Gelombang pertama itupun terjadi di akhir tahun 1800-an hingga pada pertengahan tahun 1920-an. Setidaknya 50,000 imigran dari provinsi Ottoman, Suriah sudah menjadikan AS sebagai rumah mereka sendiri. Sebagian besarnya memiliki pendidikan yang rendah dan mendapatkan pekerjaan yang rendah juga (Foad 2013). Hampir 1,2 juta imigran wilayah MENA menetap di AS dan di tahun 2016 terhitung sekitar 3\% dari 42,5 juta imigran di AS. (Cumoletti dan Batalova 2018)

Ada lima negara bagian yang menjadi wilayah penyebaran populasi imigran MENA yaitu New Jersey, California, Texas, New York, dan Michigan. Los Angles, Detroit dan New York memiliki jumlah yang signifikan. Sedangkan kawasan Detroit pada tahun 2015 sudah mencapai 100,000 imigran Timur Tengah dan 180,000 imigran Timur Tengah lainnya yang menetap di kawasan New York. Sejak 1980 hingga 2010, jumlah pendatang dari kawasan Timur Tengah dan Afrika Utara terus bertambah empat kali lipat dari sebelumnya, dari 223.000 pada tahun 1980 menjadi 861.000. Kemudian antara 2010 dan 2016, populasi imigran meningkat 36\% menjadi 1.167.000 (Zong 2019). 


\section{Dampak Keamanan Personal Masuknya Imigran Timur Tengah}

Masuknya imigran Timur Tengah berdampak pada keamanan personal/individu dari warga AS dengan memunculkan pemahaman baru yaitu Islamophobia dengan terjadinya isu 9/11 silam dan juga konflik AS-Iran hingga memandang masyarakat muslim itu adalah teroris. Hal yang melatarbelakangi Islamophobia adalah perbedaan antara kebiasaan warga AS pada umumnya dengan muslim imigran, dimana terdapat perbedaan peradaban antar keduanya yang menunjukan faktor ketidakseimbangan.

Brandon Hwang menyimpulkan bahwa kesulitan pada proses intergrasi dan asimilasi budaya muslim imigran Timur Tengah dengan budaya AS didasarkan pada citra negatif yang dikabarkan media. Berdasarkan faktor keagamaan ini, warga negara AS lebih menganggap imigran Timur Tengah sebagai penganut agama yang sangat fanatik apalagi latar belakang negara dengan isu terorisme terbanyak yaitu dari negara Timur Tengah. Oleh karena itu, hal tersebut menimbulkan ancaman keamanan personal tersendiri bagi warga AS jika menjalani kehidupan bersama dengan pengungsi dari negara dengan isu terorisme yang ekstrem.

Menurut hemat penulis, keamanan individu terbagi menjadi dua golongan, yaitu golongan pro dan kontra. Masuknya imigran Timur Tengah bagi sebagian masyarakat AS tidak dirasakan sebagai ancaman dan mereka selalu terbuka bagi imigran mana pun yang ingin masuk ke AS. Golongan yang dimaksudkan tersebut adalah golongan yang menentang kebijakan Trump yang menutup semua akses bagi imigran asing yang ingin masuk ke AS terutama imigran Timur Tengah. Dengan demikian, sebagian golongan yang kontra ini akan mendapati rasa malu dengan ketidaksesuaian atas visi misi AS dimana semua orang bisa masuk ke AS. Mereka menyarankan imigran Timur Tengah dapat masuk dengan syarat adanya protokol keamanan yang ketat agar tidak terjadinya kericuhan dan oknum-oknum imigran asing yang ingin merusak negara AS (The National Academies Press 2015).

Berbeda dengan kontra, golongan yang pro dapat dikatakan sudah terpengaruh atas doktrin Islamphobia sehingga takut akan imigran muslim dilatarbelakangi oleh peristiwa 9/11 silam. Ini mengakibatkan ketiadaan kepercayaan lagi terhadap imigran muslim untuk datang ke AS. Maka munculah Islamophobia yang dimana kata itu merupakan julukan bagi orang yang anti terhadap orang-orang islam dan kepercayaannya sehingga hal ini dinilai sebagai tindakan rasis dan tidak menghargai hak asasi manusia itu sendiri. Keberadaan imigran Timur Tengah juga dinilai dapat memicu perpecahan dan mengikis aspek budaya masyarakat AS. (The National Academies Press 2015).

Islamophobia sebagai dampak masuknya imigran Timur Tengah terhadap keamanan personal memicu berbagai aksi yang tidak menunjukkan toleransi atau rasis seperti pembakaran Al-Quran, protes anti-masjid, dan pemberitaan media yang berlebihan dalam memperlihatkan bahwa Islam merupakan merupakan agama terorisme. Masyarakat muslim di AS pun juga terdampak langsung seperti menjadi korban kekerasan fisik khususnya bagi wanita muslim di AS. Tidak hanya itu, bagi karyawan muslim yang bekerja diperusahaan besar di AS seperti Google, Facebook, dan Microsoft juga merasa khawatir jika mereka akan dipulangkan ke negara asal mereka yang padahal mereka sangat memliki kredibilitas dibidang teknologi (Khaled 2016). 


\section{Kebijakan Amerika Serikat Era Donald Trump Merespon Imigran Timur Tengah}

Adanya para imigran yang berasal dari Timur Tengah memberikan dampak cukup serius bagi AS terutama dalam keamanan personal masyarakat domestik AS. Untuk itu, keputusan pembuatan kebijakan luar negeri AS ditentukan sebagai respon baik secara internal maupun eksternal dari adanya dampak masuknya imigran tersebut. Seperti para ahli mengatakan bahwa Islam adalah perdamaian, Namun, disisi lain Trump memutar balikkan pernyataan tersebut bahwa Islam membenci kita. Hal inilah yang memicu perpecahan di masyarakat. Dengan Trump memakai bahasa kebencian, terdapat banyak sekali aksi-aksi yang tidak menunjukan toleransi atau rasis seperti pembakaran Al-Quran, protes anti-masjid, dan terkejam adalah pemberitaan media itu sendiri yang melebih-lebihkan pada bagian komentar dari artikel berita. Trump lebih nampak seperti Islamophobia yang membakar masjid, daripada Islamophobia di kantor politik yang mendukung pengawasan masjid (Khaled 2016).

Oct. 21, 2015: On Fox Business, Trump says he would "certainly look at" the idea of closing mosques in the United States.

Nov. 30, 2015: On MSNBC, a reporter asked Trump if he thinks Islam is an inherently peaceful religion that's been perverted by a small percentage of followers or if it is an inherently violent religion. Trump responded: "Well, all I can say ... there's something going on. You know, there's something definitely going on. I don't know that that question can be answered." $\mathrm{He}$ also said: "We are not loved by many Muslims."

Nov. 30, 2015: On MSNBC, a reporter asked Trump if he thinks Islam is an inherently peaceful religion that's been perverted by a small percentage of followers or if it is an inherently violent religion. Trump responded: "Well, all I can say ... there's something going on. You know, there's something definitely going on. I don't know that that question can be answered." $\mathrm{He}$ also said: "We are not loved by many Muslims."

March 9, 2016: On CNN, Trump said: "I think Islam hates us. There's something there that - there's a tremendous hatred there. There's a tremendous hatred. We have to get to the bottom of it. There's an unbelievable hatred of us."

Sumber: Jenna Johnson and Abigail Hauslohner; "II think Islam hates us": A timeline Trump's comments about Islam and Muslims."

(https://www.washingtonpost.com/news/post-politics/wp/2017/05/20/)

Selain itu, kebijakan AS di era Trump cenderung bertolak belakang dengan era pemerintahan Obama yang cenderung lebih mengakomodasi dan soft terhadap imigran dari Timur Tengah. Setidaknya ada tiga kebijakan yang dikeluarkan AS untuk merespon keamanan individu/personal domestik demi keamanan negara AS, tentunya untuk mengurangi tindakan yang diduga praktik terorisme. Oleh sebab itu, AS mengambil sikap untuk memberlakukan beberapa kebijakan terkait masalah imigran Timur Tengah yaitu:

\section{Kebijakan Border Security and Interior Enforcement}

Pada 23 Januari 2017, perintah eksekutif memutuskan untuk mengumumkan kebijakan luar negeri terkait keamanan perbatasan, berjudul "Border Security and Immigration Enforcement Improvements." Hal ini berimplikasi pada beberapa bidang 
hak asasi manusia yang dianggap lemah antara lain membatasi peluang pencarian suaka, memperluas dan memperkuat kebijakan penahanan, meningkatkan penegakan hukum di sepanjang perbatasan AS-Meksiko dan membangun tembok perbatasan sepanjang 2.000 mil di wilayah tersebut (Pierce 2018). Pierce (2018) menjelaskan bahwa latar belakang pembangunan tembok perbatasan antara ASMeksiko ini adalah salah satu janji yang paling diperhatikan pada masa kampanye Trump dalam pencalonan presiden. Dengan penggunaan dana yang ditetapkan, Department of Homeland Security (DHS) atau Departemen Keamanan Dalam Negeri atas desakan dari Gedung Putih mulai membuka proses penawaran pembangunan dengan memperhatikan model pembangunan tembok perbatasan tersebut di tahun 2017. Kemudian pada Oktober 2017, tidak lama desain dari pembangunan tembok perbatasan tersebut terselesaikan. Setelah desain tembok perbatasan selesai, para jajaran administrasi AS mengalami pertentangan oleh berbagai pihak di lingkungan domestik sehingga pembangunan tembok perbatasan tersebut dapat dimulai pada pertengahan tahun 2018.

Selain menanggapi melalui peningkatan pembangunan perbatasan dan fasilitas penahanan, pemerintahan Trump juga menyaring tugas penempatan petugas suaka dan imigrasi, seperti melakukan wawancara tentang proses keimigrasian. Trump juga mengeluarkan pedoman pada otoritas penahanan untuk menghentikan "Catch and Release", serta memerintahkan penahanan imigran yang tidak mematuhi hukum (Pierce 2018). Pada Januari 2017 terdapat penandatanganan Perintah Eksekutif yang dilakukan Trump dalam menghentikan tindakan "Catch and Release". Lalu pada April 2017, untuk memperkuat dua kebijakan border security dan interior enforcement, Departemen Kehakiman AS juga mengimplementasikan dengan mengeluarkan memo secara administratif. Memo tersebut berisi penekanan yang memerintahkan kepada Jaksa Federal agar lebih memprioritaskan penuntutan pelanggaran imigrasi kriminal, seperti masuk secara ilegal dan penyelundupan (Pierce 2018).

Mengambil data dari Center for Migration Studies of New York (2017), pada era Obama jumlah pengungsi cenderung meningkat, dimana jumlah pengungsi meningkat dari 85.000 pada 2016 menjadi 110.000 pada 2017. Kemudian di era Presiden Trump saat ini, tindakan administratif cenderung mengurangi jumlah pengungsi. Tindakan administratif yang dilakukan ditujukan untuk menjaga keutuhan keamanan nasional ternyata mampu mereduksi sebanyak 6.000 jiwa pada 2017 dan menerima sedikitnya 53.716 pengungsi di tahun yang sama. Pada 2018, Trump menguranginya menjadi 45.000 pengungsi. Oleh karena itu, jumlah pengungsi yang dianggap berkurang di AS merupakan level terendah sejak 1980 (Selee 2017). Dalam Interior Enforcement, kongres dan pihak eksekutif perlu melakukan tindakan dalam meningkatkan hukuman untuk berbagai kejahatan keimigrasian.

Penegakan imigrasi Trump mendorong DHS untuk menetapkan yurisdiksi tertentu sebagai yurisdiksi suaka. Selain itu, Trump juga menyetujui lembaga penegak hukum negara bagian untuk bertindak sebagai agen imigrasi. Ini bertujuan untuk menahan atau menangkap para imigran. Selain itu Trump juga kemudian mengakhiri Priority Enforcement Program (PEP) yang dibuat pada pemerintahan Obama dan melanjutkan rencana yang melibatkan yurisdiksi lokal untuk menghilangkan tahanan imigran ilegal selama penahanan. (Center for Migration Studies 2017). Kebijakan tersebut juga menekankan pada perluasan daftar prioritas non-warga negara yang akan dideportasi kepada siapa pun yang dituduh melakukan pelanggaran atau tindak pidana seperti penyalahgunaan 
prosedur, dugaan penipuan atau kesalahpahaman yang disengaja, dan semua hal yang berkaitan dengan aktivitas yang merugikan masyarakat (Center for Migration Studies 2017).

Selain menghentikan PEP, pemerintahan Trump juga menghentikan program Deferred Action for Child Arrival (DACA) dan Deferred Action for Parents and Legal Permanent Residents of the United States (DAPA) menjadi bagian dari rencana Dream Act. Program DACA sendiri sebelumnya dimulai pada pemerintahan era Obama pada 2012, dengan realisasi dari bentuk pemberian perlindungan kepada pengungsi. Program ini memberikan perlindungan agar tidak dideportasi bagi 690.000 imigran ilegal yang masuk ke AS dan lebih mengkategorikan usia anakanak (Pierce 2018). Pada 5 September 2017, pemerintahan Trump secara resmi mengumumkan pembatalan rencana DACA sehingga ini menghentikan fasilitas yang diberikan bagi pencari suaka.

\section{Perintah Eksekutif tentang Pengungsi dengan "Protecting the Nation from Terrorist Attacks by Foreign Nationals melalui Travel ban}

Pada 27 Januari 2017, Trump menandatangani suatu Perintah Eksekutif dengan tema "Protecting the Nation from Terrorist Attack by Foreign Nationals". Salah satu poin penting dalam kebijakan tersebut adalah diadakannya Travel ban atau larangan perjalanan ke AS. Ini dilakukan dengan menangguhkan pemberian visa terhadap beberapa negara yang mayoritas memeluk agama Islam seperti Iran, Suriah, Irak, Sudan, Somalia, Libya dan Yaman kecuali Arab Saudi. Ini juga ditambah dengan menghentikan program penerimaan pengungsi selama 120 hari (Center for Migration Studies 2017). Hal tersebut berkaitan dengan perlindungan kepada warga negara AS dari serangan teroris oleh warga negara asing dan memastikan bahwa semua orang yang diterima oleh AS memiliki pandangan dan prinsip yang sama (Selee 2017). Kebijakan Trump lebih mengarah pada pelarangan yang mengkhususkan pada imigran asal negara mayoritas Muslim sebagai bentuk upaya agar terhindar dari percobaan sebagai alat perekrutan oleh kelompok teroris. Hal tersebut memang diklaim sebagai langkah-langkah AS yang dianggap memusuhi islam. Namun, terdapat kenyataannya para pengungsi pun melakukan migrasi dikarenakan melarikan diri dari penganiayaan oleh kelompok ekstremis seperti Islamic State of Iraq (ISIS) dan the Levent di tempat asalnya. (Center for Migration Studies 2017).

Dalam laporan Center for Migration Studies (2017) menjelaskan bahwa dalam hal pengendalian pengungsi, kebijakan era Trump turut mengurangi jumlah pengungsi dari 110,000 menjadi setengahnya yaitu 50,000 jiwa yang akan diterima pada 2017. Kemudian transfer pengungsi dari Suriah dihentikan tanpa batas waktu. Selain itu, dikeluarkan pula sistem atau mekanisme penyaringan untuk mengatur masuknya WNA, dan ditegaskan bahwa Departemen Keamanan Dalam Negeri harus segera melengkapi sistem pelacakan imigrasi bagi pengungsi. Trump menjelaskan bahwa proses penerbitan visa untuk negara muslim melalui penilaian yang sangat kritis dan tidak mudah guna mencegah peristiwa 9/11. Sejak awal 2017 hingga proses pengembangan tahun 2018, travel ban sudah mengalami tiga kali perubahan, dua di antaranya yakni melalui perintah eksekutif dan satu perubahan pengumuman presiden.

Travel ban 1.0 dimulai dengan adanya perintah eksekutif tentang penangguhan program pemukiman kembali di AS selama 120 hari, yang kemudian hal tersebut dikuatkan kembali dengan pemindaian melalui proses penyaringan secara sistematis guna menjaga keamanan nasional. Travel ban 1.0 menekankan 
pada proses yang memungkinkan untuk tahapan selanjutnya dari pengungsi ditinjau dalam kasus per kasus yang sebelumnya telah ada dalam perkembangan keimigrasian dan menangguhkan kembali pemukiman pengungsi asal Suriah tanpa batas waktu (Center for Migration Studies 2017). Di dalam travel ban I diatur juga cara para imigran yang harus melalui beberapa tahapan sebelum masuk ke AS, misalnya pemeriksaan oleh agen federal dan wawancara oleh petugas dari DHS. Hal ini bertujuan untuk mengetahui kelayakan dari pengungsi tersebut yang dilihat dari latar belakang pemohon serta rekam medis (Wadhia 2018). Pemerintah AS juga mempunyai website media sosial sendiri untuk menyiarkan informasi perkembangan proses penyaringan imigran yang memuat lebih spesifik dari penggambaran proses penyaringan bagi para pengungsi.

Travel ban 2.0 diberlakukan setelah Presiden Trump menandatangani perubahan Perintah Eksekutif menjadi travel ban 2.0 tepat pada tanggal 6 Maret 2017. Perubahan ini mengarah pada penghapusan salah satu negara yaitu Irak, sehingga menjadi enam Negara yaitu Iran, Somalia, Libya, Sudan, Yaman serta Suriah yang dilarang masuk ke AS. Penghapusan Irak dalam perjalanan jangka waktu 90 hari ini namun tetap melanjutkan pembekuan program penerimaan pengungsi dalam jangka 120 hari pada enam negara sisanya, dan memotong setengah jumlah pengungsi (Wadhia 2018).

Terdapat tiga perbedaan dalam perubahan yang membedakan antara Travel Ban 2.0 dengan travel ban sebelumnya yakni:

1. Pertama, Travel Ban 2.0 memiliki waktu yang tidak pasti untuk mencabut larangan bagi pengungsi Suriah. Larangan bagi pengungsi Irak juga telah dicabut. Tanggal berlakunya regulasi tersebut sempat tertunda sekitar sepuluh hari. Aturan ini menjelaskan lebih jauh kebingungan yang terjadi di Travel Ban 1.0.

2. Kedua, di AS, penduduk tetap yang sah atau pemegang kartu hijau dapat dibebaskan dari pembebasan bersyarat sesuai aturan travel ban 2.0.

3. Penduduk tetap akan menerima bantuan pengungsi dan akan diizinkan untuk melakukan perjalanan dengan syarat telah memperoleh visa diplomatik untuk bepergian.

Tulisan Wadhia (2018) juga menjelaskan perubahan skema travel ban terlihat dari melepaskan beberapa poin dalam aturan sebelumnya diantaranya: pertama, penolakan imigran masuk dapat menyebabkan kesulitan nasional tersendiri. Kedua, kedatangan imigran juga tidak akan menimbulkan ancaman keselamatan publik maupun keamanan nasional. Ketiga, kedatangan dari imigran merupakan kepentingan nasional. Ketiga elemen ini telah dihilangkan di Travel ban 2.0 dan tidak didefinisikan dengan jelas dalam undang-undang imigrasi.

Travel ban 3.0 dikeluarkan dalam bentuk Presidential Proclamation pada tanggal 24 September 2017. Hal tersebut merupakan hasil proklamasi yang sama namun tidak memiliki identifikasi seperti perintah eksekutif. Dalam keadaan seperti ini, beberapa perubahan telah terjadi dalam tatanan kebijakan negara terlarang seperti Korea Utara, Suriah, Somalia, Iran, Libya, Chad, Yaman dan Venezuela. Beberapa negara tersebut ditentukan atas latar belakang menghindari ancaman yang telah dirasakan oleh AS. Perubahan yang terlihat dalam perintah ini yakni menetapkan Sudan sebagai negara yang dikeluarkan dari blacklist. Sama dengan travel ban sebelumnya, travel ban 3.0 juga terdapat pula pembatasan waktu yang tidak dapat ditetapkan durasi waktu yang pasti untuk warga negara dari beberapa negara yang disebutkan sebelumnya (Center for Immigrants' Rights Clinic 2018). 
Dalam perjalanannya, kebijakan AS ini menghambat masuknya pengungsi dan turis, terutama yang berasal dari tujuh negara yang masuk dalam daftar ke AS. Kebijakan ini juga mengambil langkah-langkah untuk meminimalkan jumlah permohonan pengungsi, bahkan lebih dari tahun sebelum terciptanya program imigrasi pada tahun 1980. Trump juga memberikan pekerjaan formal, membatalkan program DACA dan memberikan bantuan sementara kepada sekitar 690.000 imigran resmi yang masuk ke AS dan sebagian besarnya adalah dari anak-anak. (Center for Immigrants' Rights Clinic 2018). Berdasarkan data Center for Immigrants' Rights Clinic (2018), tindak selanjutnya dari kebijakan ini, yaitu mengakhiri Temporary Protected Status (TPS) bagi Nikaragua, Haiti dan Sudan. Kemudian pada tahun 2018 terdapat himbauan bahwa Salvador dan Honduras mungkin dapat kehilangan perlindungan dari adanya pemindahan pengungsi, dan izin kerja. Pada 10 April 2018 peraturan DHS menyebutkan bahwa Presiden Trump kembali menandatangani terkait dengan penghapusan Republik Chad.

\section{KESIMPULAN}

Berdasarkan konsep keamanan manusia, Ionjakan jumlah imigran Timur Tengah dianggap menciderai keamanan personal bagi masyarakat AS. Sebelumnya terdapat faktor sejarah terjadinya isu 9/11 dan isu terorisme lainnya di mana tindakan terorisme yang disebut berasal dari negara Timur Tengah. Hal tersebut juga yang menyebabkan paham baru di negara AS yaitu islamophobia. Isu terorisme dan kemunculan paham islamophobia menjadi ancaman personal bagi masyarakat domestik AS. Selain itu, lonjakan jumlah imigran menyebabkan ancaman penduduk domestik dalam persaingan di lapangan pekerjaan. Untuk itu, dengan adanya kebijakan luar negeri era Trump merupakan respon Negara AS yang perlu dikuatkan untuk mengatasi adanya ancaman terorisme dan hilangnya lapangan pekerjaan akibat proses imigrasi tersebut, hingga mengancam keamanan personal masyarakat AS.

Respon AS era Trump terhadap isu imigran diperlihatkan dengan kebijakan luar negerinya seperti (1) kebijakan border security and interior enforcement, serta adanya (2) perintah eksekutif tentang pengungsi dengan "Protecting the Nation from Terrorist Attacks by Foreign Nationals melalui travel ban 1.0, travel ban 2.0, dan travel ban 3.0. Kebijakan-kebijakan ini diambil sebagai langkah nyata untuk meminimalkan jumlah permohonan pengungsi yang masuk AS, khususnya pengungsi Timur Tengah. Dengan kebijakan luar negeri Trump ini, AS di mata Internasional dianggap mampu memainkan perannya sebagai negara yang konsisten terhadap prinsip American Values dengan tetap menerapkan penerimaan imigran yang berasal dari Timur Tengah namun dengan memperhatikan dampak keamanan warga negara AS secara lebih serius.

\section{REFERENSI}

Beydoun, Khaled A. 2016. "Donald Trump: The Islamophobia president: Trump rose to power with an Islamophobic campaign and Islamophobia now will become his official policy." https://www.aljazeera.com/opinions/2016/11/9/donaldtrump-the- islamophobia-president/.

Cumoletti Mattea, Batalova Jeanne. "Middle Eastern and North African Immigrants in the United States." https://www.migrationpolicy.org/article/middle-eastern-and- 
north- african-immigrants-united-states.

Center for Migration Studies of New York. 2017. "President Trump's Executive Orders on Immigration and Refugees." https://cmsny.org/trumps-executiveorders-immigration-refugees/.

IOM. 2013. "International Migration, Health and Human Rights." https://www.ohchr.org/Documents/Issues/Migration/WHO_IOM_UN OHCHRPublication.pdf.

Foad, Hisham S. 2013. "Waves of Immigration from the Middle East to the United States." https://www.aeaweb.org/aea/2014conference/program/retrieve. php?pdfid=416

Hampson, F.O. 2013. "Human Security", in Security Studies an Introduction $2^{\text {nd }}$ Edition. New York: Routledge.

Holsti, K. J. 1968. International Politics: A Framework for Analysis. Englewood Cliffs N.J. Prentice-Hall.

Ikbar, Yanuar. 2014. Metodologi dan Teori Hubungan Internasional. Bandung: PT Refika Aditama.

James N. Rosenau. 1980. The Scientific Study of Foreign Policy. New York: The Free Press.

Pierce, Sarah dkk. 2018. "Trump's First Year on Immigration Policy : Rhetoric vs. Reality." Migration Policy Institute: Washington, DC. https://www.migrationpolicy.org/research/trump-first-year- immigration-policyrhetoric-vs-reality.

Saba, Usi. 2015. "Kenapa Amerika Jadi Tujuan Imigran Muslim?," https://www.kompasiana.com/usisaba/5668356663afbd1d12d5c843/k enapaamerika-jadi-tujuan-imigran-muslim.

Selee, Andrew, dan Sarah Pierce. 2017. "Immigration Under Trump: A Review of Policy Shifts in the Year Since the Election." Migration Policy Institute:New York, diakses dalam https://www.migrationpolicy.org/research/immigrationunder-trump- review-policy-shifts.

Syekhnurjati. 2018. Sejarah dan Faktor Migrasi Muslim Lebanon ke Amerika Serikat tahun 1880-1990. Cirebon: IAIN Cirebon.

The Nations Academies Press. 2015. "The Integration of Immigrants into American Society." https://www.nap.edu/read/21746/chapter/3

United Nation Development Programme. 2010 "Human Development Report 1994." http://hdr.undp.org/sites/default/files/reports/255/hdr_1994_en_compl ete_nostats.pdf.

United Nation High Commissioner Refugees. "Displacement in Central America." https://www.unhcr.org/displacement-in-central- america.html.

United Nation High Commissioner Refugees. 2018 "What is Refugees? Definition and Meaning." https://www.unhcr.org/refugees.html.

Wadhia, Shoba Sivaprasad. 2018. National Security, Immigration and the Muslim Bans. Washington and Lee Review, Volume 75, Issue 3, Article 9. Penn State Law, University Park.

Zong Jie, Batalova Jeanne. "Middle Eastern and North African Immigrants in the United Stares." https://www.migrationpolicy.org/article/middle- eastern-andnorth-african-immigrants-united-states-3. 